Teresa M.P. Gomes, António P. Mendes de Sousa, Yuri I. Belenkiy and Dmitry V. Evtuguin*

\title{
Xylan accessibility of bleached eucalypt pulp in alkaline solutions
}

https://doi.org/10.1515/hf-2019-0023

Received January 29, 2019; accepted April 25, 2019; previously published online June 21, 2019

\begin{abstract}
The accessibility of glucuronoxylan from a refined, bleached Eucalyptus globulus industrial kraft pulp in 0-18\% aqueous $\mathrm{NaOH}$ solution at room temperature $\left(25^{\circ} \mathrm{C}\right)$ was studied. The extraction profile revealed a maximum extraction of xylan in the pulp at about $10-12 \% \mathrm{NaOH}$ concentration and was explained by the maximum swelling of the pulp according to the Gibbs-Donnan equilibrium. The kinetics of xylan removal and the monitoring of its structural features were performed at 5 and $10 \% \mathrm{NaOH}$ concentrations. The maximum yields of xylans with $10 \%$ and $5 \% \mathrm{NaOH}$ were as high as $90 \%$ and $60 \%$ for $2 \mathrm{~h}$ extraction, respectively. The structural features of xylan were assessed by acid methanolysis and one-dimensional (1D)/two-dimensional (2D) nuclear magnetic resonance (NMR), and the molecular weight by size exclusion chromatography (SEC). The xylan extracted with $10 \% \mathrm{NaOH}$ had a slightly higher molecular weight and a lower branching with uronic moieties than the xylan extracted with $5 \% \mathrm{NaOH}$. The former was less pure (contained more $\beta$-cellulose) than the latter. Structural studies by NMR resulted in the conclusion that there are at least two types of xylans removed from the pulp: one xylan with relatively high 4-O-methyl- $\alpha$-D-glucuronosyl [MeGlcA- $(1 \rightarrow$ ] and $[\rightarrow 2)$-MeGlcA- $(1 \rightarrow]$ substituents and another xylan with a much lower substitution with uronic residues.
\end{abstract}

Keywords: Eucalyptus globulus, fibril aggregation, kraft pulping, refinability, xylan

\section{Introduction}

$O$-acetyl-(4-O-methylglucurono) xylan, or simply xylan for short, is the major hemicellulose in hardwoods (up to

\footnotetext{
*Corresponding author: Dmitry V. Evtuguin, CICECO/Department of Chemistry, University of Aveiro, 3810-193 Aveiro, Portugal, e-mail: dmitrye@ua.pt

Teresa M.P. Gomes: CICECO/Department of Chemistry, University of Aveiro, 3810-193 Aveiro, Portugal

António P. Mendes de Sousa: Research Institute on Forestry and Paper (RAIZ), Quinta de S. Francisco, Eixo 3801-501, Portugal Yuri I. Belenkiy: St. Petersburg Forest Technical University, Institutsky per. 5, 194021 St. Petersburg, Russian Federation
}

$90 \%$ of all hemicelluloses) and is constituted of the main backbone built by ( $1 \rightarrow 4)$-linked $\beta$-D-xylopyranosyl units $(\mathrm{Xyl} p)$ ramified with terminal $(1 \rightarrow 2)$-linked 4-O-methyl$\alpha$-D-glucuronosyl residues (MeGlcA) at an approximate Xylp:MeGlcA proportion of 10 to 1 (Sjöström 1993; Ebringerová 2006). Hardwood xylans are partially acetylated [degree of substitution (DS) $=0.5-0.6$ ] and possess a molecular weight of ca. 30-40 kDa. Due to the particular resistance to degradation under alkaline conditions, xylans revealed relatively high retention in kraft pulps thus contributing noticeably to their yield (Sjöström 1993; Pinto et al. 2005a). Xylans play an extremely important role in the papermaking properties of bleached kraft pulps (BKP) providing improved refinability and strength properties of paper (Clark 1985; Hubbe 2014). However, the excessive xylan content may be prejudicial for some specific papermaking or non-papermaking applications (Sixta 2006; Pääkkönen et al. 2016). On an industrial scale, the desired removal of xylan from cellulosic pulps can be achieved both by cold caustic extraction $\left(\mathrm{CCE}, \mathrm{T}<40^{\circ} \mathrm{C}\right.$ ) and hot caustic extraction ( $\mathrm{HCE}, \mathrm{T}>40^{\circ} \mathrm{C}$ ), the latter being less appropriate when the excessive degradation of polysaccharides is critical (Sixta 2006).

Alkaline extraction of hardwood bleached kraft pulps (HBKP) is a powerful tool for its modification to different papermaking and chemical/physical processing purposes. Thus, the same conventional paper-grade HBKP can be converted to pulp for special papers, to dissolving pulp or to the pulp for nanocellulose production by means of targeted elimination of the hemicellulose fraction using CCE (Sixta 2006; Saukkonen et al. 2012; Arnoul-Jarriault et al. 2014; Laine et al. 2015; Li et al. 2015; Quaresma et al. 2015; He et al. 2017). Extracted xylans which are valuable raw materials for packaging applications can be used for the production of xylitol, xylooligosaccharides (XOS), bio-detergents, biocomposites, etc. (Deutschmann and Dekker 2012).

Alkaline extraction is also a common instrument in laboratory practice to isolate xylan from pulps or other cellulosic materials to quantify or to study its structural characteristics (Browning 1967; Vuorinen and Alén 1999). Altering the alkali concentration, temperature and extraction time, the extent and chemical composition of the xylans removed may be substantially varied (Browning 1967; Vuorinen and Alén 1999). This basic knowledge is 
essential to planning new strategies for BKP modification and to provide the basis for the alkali extraction as an analytical tool to assess the xylan structural features in pulps. Such information is just fragmentary for Eucalyptus globulus BKP and was the main goal of this study. The kinetics of industrial eucalyptus BKP under CCE conditions was evaluated and the structural features of the removed xylans were related to the extraction conditions.

\section{Materials and methods}

Materials: The industrial elemental chlorine-free (ECF) bleached (ca. 91\% ISO) E. globulus kraft pulp was supplied by the Navigator Company-Industrial Complex in Cacia (Portugal). After the preliminary refining to ca. $60^{\circ}$ (Schopper-Riegler degree) using the Escher Wyss RL1 refiner (Zurich, Switzerland), the pulp was dried in small flocks to ca. $20 \%$ humidity. The pulp was extracted using aqueous $\mathrm{NaOH}$ solution of different concentrations $(2-18 \%, w / w)$ for $2 \mathrm{~h}$ at $5.0 \%$ consistency being preliminary swollen in water for $5 \mathrm{~h}$. In order to diminish the contribution of oxidation and peeling reactions, the extraction solution contained $0.01 \% \mathrm{NaBH}_{4}(\mathrm{w} / \mathrm{w})$. The extraction was carried out at $25^{\circ} \mathrm{C}$ in a thermostatic bath under moderate mechanical stirring (ca. $120 \mathrm{rpm}$ ) in triplicate. After the extraction, the pulp was filtered off and quickly transfered to the excess of distilled water being further washed on the filter until neutral $\mathrm{pH}$. The extracted pulp was dried at $60^{\circ} \mathrm{C}$ for $48 \mathrm{~h}$ and was further subjected to analyses (yield and sugar composition, Table 1). The alkaline extracts were neutralized by acetic acid until $\mathrm{pH} 4.2$ and purged into the excess of ethanol to precipitate the xylan at $4^{\circ} \mathrm{C}$ for $12 \mathrm{~h}$. The precipitated xylan was centrifuged, redispersed in water and dialyzed against water using cellophane membrane of 2000 nominal molecular weight cutoff (NMWCO) for 2 days. The purified xylan suspension was centrifuged, washed 3 times by anhydrous methanol and further freeze-dried.

Analyses: The swelling of pulp was determined as a linear expansion according to the standard method (GOST 7516-85). Briefly, 10 pulp rings cut from previously conditioned [65\% relative humidity (RH), $20^{\circ} \mathrm{C}$ ] industrial pulp sheets were strung on a metal holder between two perforated metal rings (one at the bottom is fixed and another at the top is movable) in a closed glass cylinder of $1000 \mathrm{ml}$ capacity and soaked in alkaline solutions of different concentrations for $5 \mathrm{~min}$ under pre-determined conditions $\left(20^{\circ} \mathrm{C}\right)$. After the assay, the excess of alkaline solution was allowed to drain for $5 \mathrm{~min}$ and the distance between the metal rings limiting the pack of pulp rings was registered.
The linear expansion was calculated as the difference between the heights of the metal rings before $\left(\mathrm{h}_{0}\right)$ and after $\left(\mathrm{h}_{1}\right)$ the soaking in alkaline solutions or in water [swelling, $\left.\%=\left(\left[h_{1}-h_{0}\right] / h_{0}\right) \star 100\right]$. The relative errors in the triplicate determinations did not exceed 5\%.

The pulp before and after the extraction was analyzed on neutral sugars such as alditol acetates by gas chromatography (GC) after Saeman hydrolysis (Evtuguin et al. 2003). The isolated xylans were analyzed by acid methanolysis on the sugar composition (Wedin et al. 2013) and by one-dimensional (1D, proton and carbon) and two-dimensional (2D) [correlated spectroscopy (COSY), total correlation spectroscopy (TOCSY) and heteronuclear single quantum coherence (HSQC)] in $\mathrm{D}_{2} \mathrm{O}$ at $30^{\circ} \mathrm{C}$ according to a previously published methodology (Evtuguin et al. 2003). The quantitative proton nuclear magnetic resonance (NMR) spectra of isolated xylans were recorded in $\mathrm{D}_{2} \mathrm{O}$ at $303 \mathrm{~K}$ on a Bruker AVANCE 300 spectrometer (Bruker, Wissembourg, France) operating at $300.13 \mathrm{MHz}$. The xylan was dissolved in $\mathrm{D}_{2} \mathrm{O}$ (ca $2 \% \mathrm{w} / \mathrm{w}$ ) (Acros Organics, NJ, USA), and sodium 3-(trimethylsilyl)propionate- $d_{4}$ (TMSP, $\delta 0.00$ ) (Sigma-Aldrich Chemie, Steinheim, Germany) served as an internal standard. The acquisition parameters for the proton spectra, $12.2 \mu$ s pulse width $\left(90^{\circ}\right), 16 \mathrm{~s}$ relaxation delay and 300 scans, were collected. Size exclusion chromatography (SEC) was performed in $0.1 \mathrm{M} \mathrm{LiCl} \mathrm{N,N-dimethylacetamide}$ (DMAC) (HPLC grade, Sigma-Aldrich Chemie, Steinheim, Germany) solution on a PL-GPC 110 system (Polymer Laboratories, Shropshire, UK), which was equipped with a $10-\mu \mathrm{m}$ PLgel pre-column and two $10-\mu \mathrm{m}$ PLgel columns (MIXED D $300 \times 7.5 \mathrm{~mm}$ in a series, Polymer Laboratories, Shropshire, UK), and a refractive index (RI) detector at $70^{\circ} \mathrm{C}$ (Prozil et al. 2012). The columns were calibrated with pullulans (Polymer Laboratories, Shropshire, UK) in the range of 1-100 kDa. The xylan location in the fibers was evaluated by hydrolysis kinetics with endo-xylanase (E.C. \#3.2.1.4; from Thermomyces lanuginosus of the GH 10 family) according to Salgueiro et al. (2016). The released reducing sugars (RS) were analyzed by the 3,5-dinitrosalicylic acid (DNS) method (Miller 1959). The pulp samples after the alkali extraction were never dried before enzymatic hydrolysis.

\section{Results and discussion}

\section{Xylan extraction in $\mathrm{NaOH}$ solutions of different concentrations}

Being located in the interfibrillar space, xylan macromolecules are trapped inside the cell wall carcass and aligned

Table 1: The pulp yields and xylan contents of alkali-extracted pulps $\left(25^{\circ} \mathrm{C}, 2 \mathrm{~h}\right)$.

\begin{tabular}{|c|c|c|c|c|c|}
\hline & \multicolumn{5}{|c|}{$\mathrm{NaOH}$ concentration $(\%, w / w)$} \\
\hline & 0 & 2.0 & 4.0 & 6.0 & 8.0 \\
\hline Pulp yield (\%) & 100.0 & $94.2 \pm 1.6$ & $88.1 \pm 0.8$ & $85.8 \pm 1.0$ & $79.1 \pm 0.8$ \\
\hline \multirow[t]{2}{*}{ Xylan (\%) } & $16.9 \pm 0.3$ & $15.8 \pm 0.3$ & $11.7 \pm 0.2$ & $6.4 \pm 0.1$ & $4.4 \pm 0.2$ \\
\hline & 10.0 & 12.0 & 14.0 & 16.0 & 18.0 \\
\hline Pulp yield (\%) & $75.9 \pm 0.9$ & $76.6 \pm 0.5$ & $81.6 \pm 1.2$ & $84.5 \pm 1.6$ & $86.1 \pm 0.2$ \\
\hline Xylan (\%) & $1.9 \pm 0.2$ & $1.5 \pm 0.1$ & $3.5 \pm 0.2$ & $4.8 \pm 0.4$ & $5.3 \pm 0.3$ \\
\hline
\end{tabular}


around fibrils, which hinders their removal in alkaline solutions, despite the good solubility in them (Kerr and Goring 1975; Scott 1984). Mechanical fiberizing of cellulosic pulp significantly improved the amount of extracted xylan due to the enhanced swelling of fibers (Scott 1984). For our rough estimate, the relative difference between xylan extracted from unrefined and refined eucalyptus BKP in the range of $4-10 \% \mathrm{NaOH}$ concentration may reach up to $10 \%$. Accordingly, in order to decrease the effect of cell wall morphology on the extent of xylan removal from the studied pulp, the latter was beaten before alkaline extraction. The effect of $\mathrm{NaOH}$ concentration in aqueous solution on the solubility of xylan from bleached E. globulus kraft pulp is depicted in Figure 1. Maximum removal of xylan at $25^{\circ} \mathrm{C}$ for $2 \mathrm{~h}$ was observed at a $\mathrm{NaOH}$ concentration of about $10-12 \%$. This fact was assigned mainly to the xylan
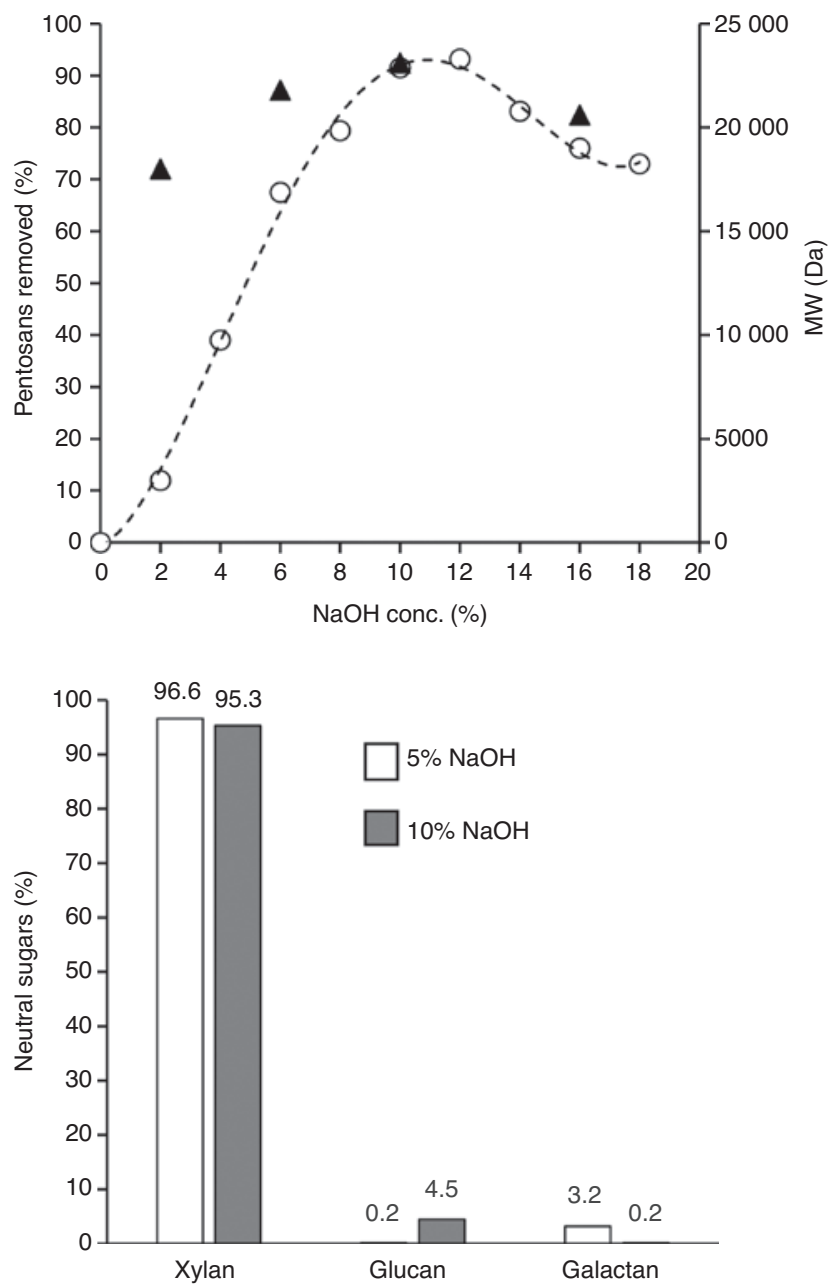

Figure 1: The effect of $\mathrm{NaOH}$ concentration in aqueous solution on the solubility of xylan from bleached $E$. globules kraft pulp is depicted. Effect of $\mathrm{NaOH}$ concentration on the removal $(\mathrm{O})$ and the molecular weight $(\boldsymbol{\Delta})$ of xylan from bleached kraft pulp (upper figure) and the neutral sugar composition of removed hemicelluloses (bottom figure). accessibility rather than to xylan solubility, because the maximum of removal was coincided with the maximum of pulp swelling in $\mathrm{NaOH}$ solutions of $0-18 \%$ (Figure 2). Pulp swelling in alkaline solutions involves the enlargement of the fibers in the transverse direction with a simultaneous slight decrease in their length and can be evaluated both by increment of pulp weight due to the enhanced hydration or by increment of pulp sample dimensions (Nikitin 1962). For most cellulosic pulps, maximum swelling occurs at $10-12 \%$ of $\mathrm{NaOH}$ concentration (Richter and Glidden 1940; Nikitin 1962; Budtova and Navard 2016; He et al. 2017) and is due to the Gibbs-Donnan equilibrium established for hydrated $\mathrm{NaOH}$ between the fiber bulk and the external solution (Krässig 1993). At the maximum swelling point of the pulp, the diffusivity of soluble low-molecular-weight cellulose chains (known as $\beta$ - and $\gamma$-cellulose) from amorphous regions and the crystallite surface of fibrils to the outer solution becomes the greatest due to the increased cell wall porosity, and this fact is used to determine the alkali resistant fraction of cellulose in pulp, known as $\alpha$-cellulose (Nikitin 1962; Budtova and Navard 2016). Changes that occurred in the porosity of the cell wall controlled the permeation of xylan macromolecules from the fibers to the outer solution, whose molecular weight reached a maximum at the highest fiber swelling corresponding to the solution of $10-12 \% \mathrm{NaOH}$ (Figure 1).

It is noteworthy that the purity and the chemical composition of the extracted xylan depended on the concentration of the alkali solution. Thus, at moderate $\mathrm{NaOH}$ concentration (e.g. 5\%), the extracted xylan did not contain the concomitant $\beta$-cellulose and revealed much more arabinogalactan, known to be chemically $(1 \rightarrow 2)$-linked to the

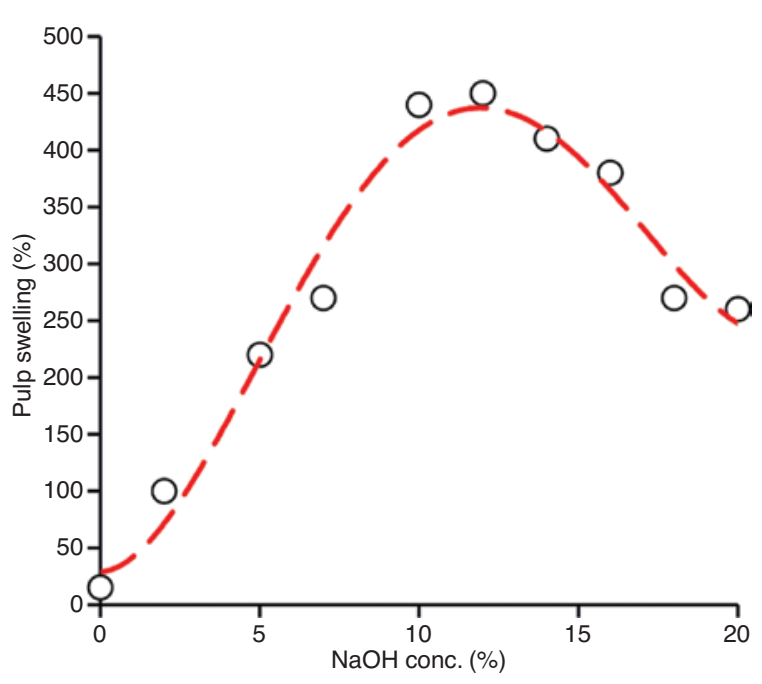

Figure 2: Effect of $\mathrm{NaOH}$ concentration on the swelling of bleached eucalypt kraft pulp. 
[MeGlcA-(1 $\rightarrow$ ]moieties attached to $\mathrm{C}(0) 2$ of the main xylan backbone (Evtuguin et al. 2003), when compared to the xylan extracted by $10 \% \mathrm{NaOH}$ solution (Figure 1). Hence, the alkali concentration used for pulp extraction not only affected the extent of the xylan removed or its molecular weight and purity, but also discriminated structurally different xylan fractions. This means structural heterogeneity of xylans in relation to their accessibility at varying alkaline concentrations in solution, which has been the subject of a more detailed study.

\section{Kinetics of xylan extraction from pulp with 5 and $10 \% \mathrm{NaOH}$ solutions}

In order to assess the changes in xylan structure depending on the alkali concentration and the extraction time,
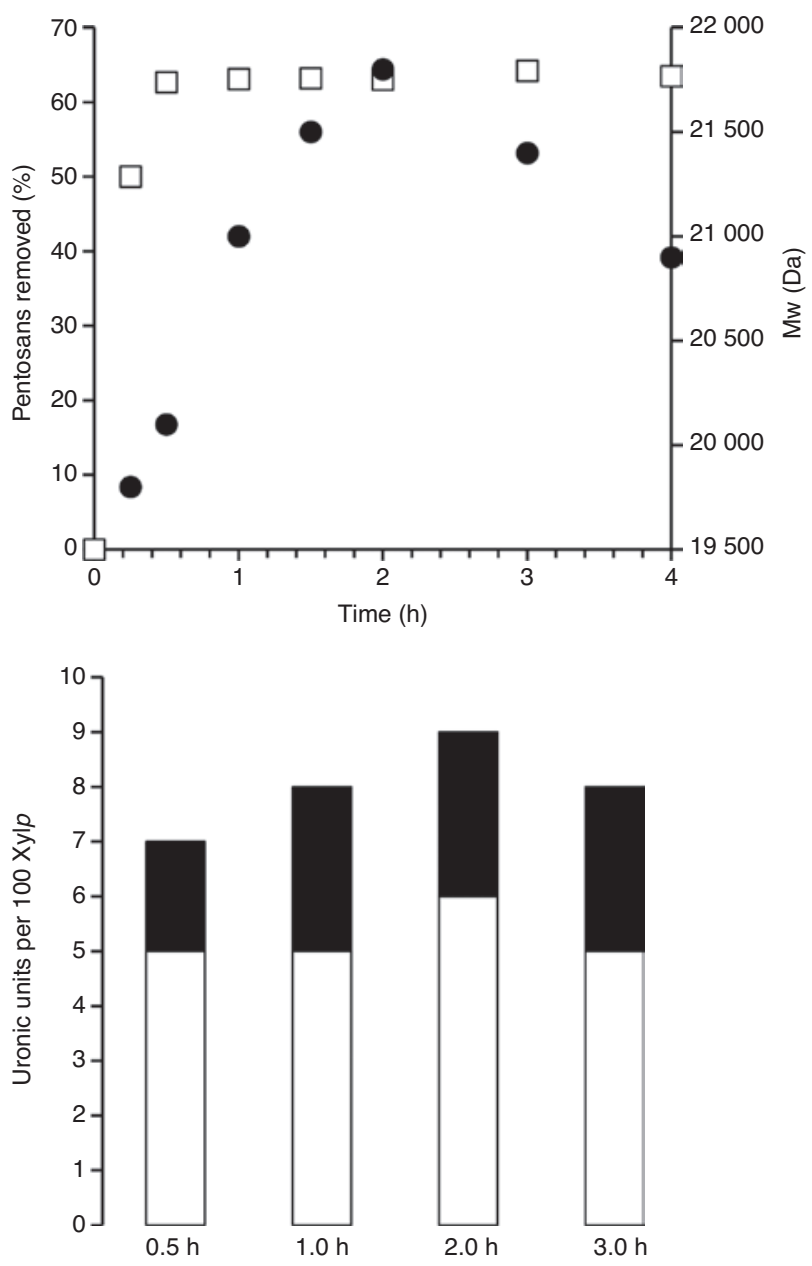

Figure 3: The kinetics of xylan extraction from pulp were studied in $5 \% \mathrm{NaOH}$ solution.

Kinetics of the xylan removal $(\square)$ and changes in its molecular weight ( ) during bleached kraft pulp extraction with $5 \% \mathrm{NaOH}$ (upper figure). The frequency of xylan backbone substitution with different uronic moieties is shown in the bottom picture. the kinetics of xylan extraction from pulp were studied in 5 and $10 \% \mathrm{NaOH}$ solutions (Figures 3 and 4). The structure of xylans isolated from alkaline extracts was confirmed by 2D NMR techniques (COSY, TOCSY and HSQC) (Evtuguin et al. 2003) and the composition by acid methanolysis (Table 2). Besides the molecular weight, the basic distinguishing structural feature was the degree of xylan backbone substitution with [MeGlcA- $(1 \rightarrow]$ and $[\rightarrow 2)-\operatorname{MeGlcA}-(1 \rightarrow]$ moieties, which was calculated by quantitative ${ }^{1} \mathrm{H}$ NMR spectra based on the chemical shifts of corresponding anomeric protons in uronic moieties at $5.28 \mathrm{ppm}$ [MeGlcA- $(1 \rightarrow]$ and at $5.42[\rightarrow 2)$-MeGlcA- $(1 \rightarrow]$ and in internal Xylp units of the backbone at $4.48 \mathrm{ppm}$ (Sousa and Amaral 2017).

The kinetics of pulp extraction with $5 \%$ and $10 \%$ $\mathrm{NaOH}$ solutions showed a very fast initial step with a
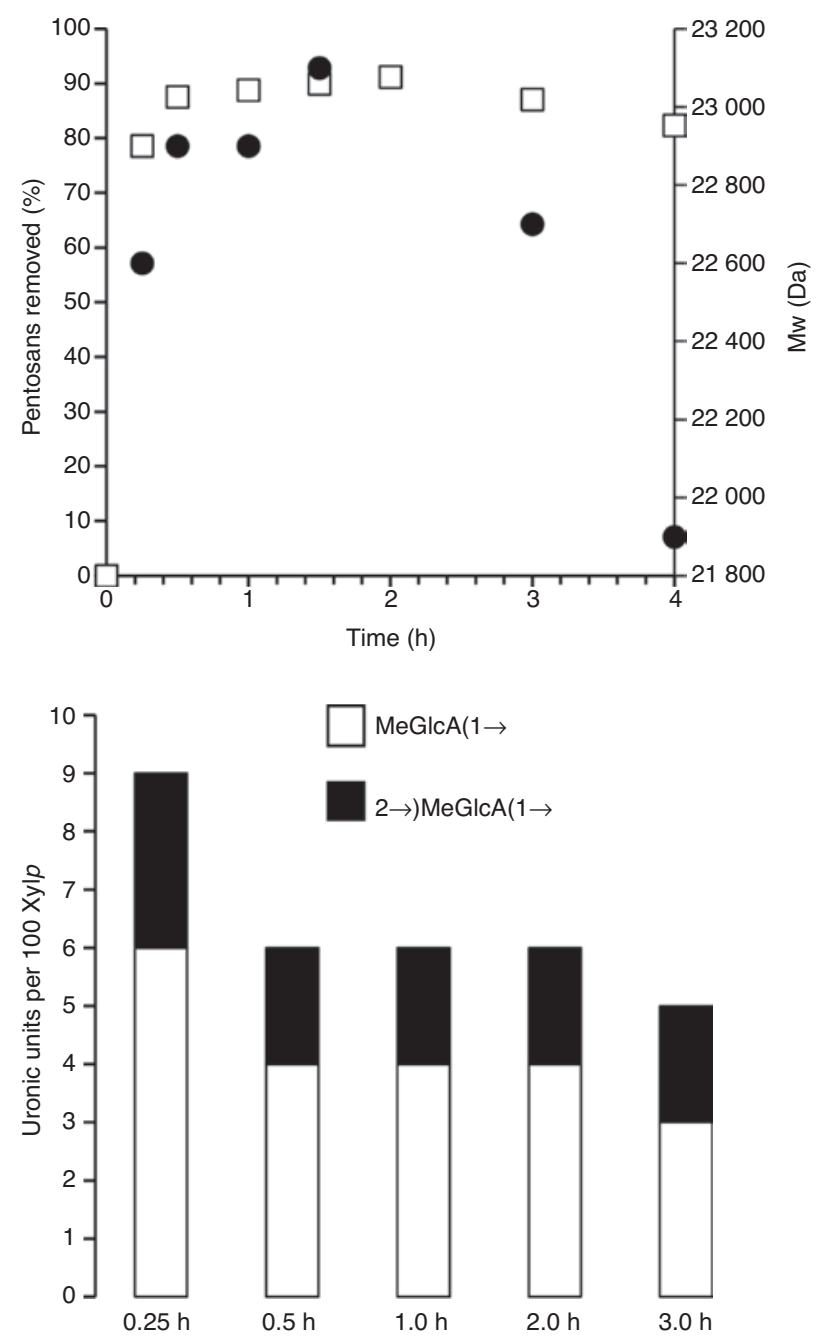

Figure 4: The kinetics of xylan extraction from pulp were studied in $10 \% \mathrm{NaOH}$ solution.

Kinetics of xylan removal $(\square)$ and changes in its molecular weight (๑) during bleached kraft pulp extraction with $10 \% \mathrm{NaOH}$ (upper figure). The frequency of xylan backbone substitution with different uronic moieties is shown in the bottom picture. 
Table 2: Analysis of isolated xylan from alkali-extracted pulp by acid methylation.

\begin{tabular}{|c|c|c|c|c|c|c|}
\hline \multicolumn{2}{|c|}{ Alkaline extraction } & \multirow[b]{2}{*}{ Xyl } & \multirow[b]{2}{*}{ 4-OMeGIcA } & \multirow[b]{2}{*}{ GalA } & \multicolumn{2}{|c|}{ Methylated residues (\%) } \\
\hline$[\mathrm{NaOH}](\%)$ & $t(h)$ & & & & Gal & Glc \\
\hline $10 \%$ & 2.0 & $92.4 \pm 0.5$ & $3.0 \pm 0.2$ & $0.8 \pm 0.1$ & $0.2 \pm 0.05$ & $3.6 \pm 0.2$ \\
\hline $5 \%$ & 2.0 & $92.6 \pm 0.6$ & $5.1 \pm 0.2$ & $0.4 \pm 0.1$ & $1.8 \pm 0.2$ & $<0.1$ \\
\hline
\end{tabular}

duration of 15 min corresponding to the removal of a major part of xylan, followed by a slow kinetics of xylan removal until ca. $2 \mathrm{~h}$. After $2 \mathrm{~h}$ in $10 \% \mathrm{NaOH}$ or after $3 \mathrm{~h}$ in $5 \% \mathrm{NaOH}$ solution, the amount of xylan removed from the pulp decreased noticeably (Figures 3 and 4). This is explained by partial xylan degradation in alkaline solutions, as also follows from the decreasing of molecular weight of isolated xylan from the alkaline extracts and the diminishing of xylan branching with uronic moieties vulnerable to alkaline hydrolysis (Pinto et al. 2005a,b). More than $60 \%$ and $90 \%$ of xylan was removed from the pulp for the 2-h extraction with $\mathrm{NaOH}$ solutions of $5 \%$ and $10 \%$, respectively. Moreover, the molecular weight of xylan extracted by $10 \% \mathrm{NaOH}$ was slightly higher than that of xylan extracted by 5\% NaOH (Figures 3 and 4). Interestingly, for the same extraction conditions $(4 \% \mathrm{NaOH}$, $20-25^{\circ} \mathrm{C}, 1 \mathrm{~h}$ ), the amount of extracted xylan from refined eucalyptus BKP (ca. 40\%) was notably higher than that from unrefined birch BKP (ca. 33\%) reported previously (Laine et al. 2015). This again emphasizes the importance of mechanical destructuration of fibers before the alkaline extraction of xylan.

The frequency of substitution with the uronic moieties of the xylan extracted with $5 \% \mathrm{NaOH}$ reached the maximum in the maximum removal of xylan from the pulp after $2 \mathrm{~h}$ of extraction (Figure 3). In contrast, the substitution with the uronic moieties of the xylan extracted with $10 \% \mathrm{NaOH}$ decreased in the maximal xylan removal after $2 \mathrm{~h}$ of extraction (Figure 4) being almost half of that for the xylan extracted with $5 \% \mathrm{NaOH}$ (Figure 3). These features were interpreted in terms of different xylan fractions extracted with 5 and $10 \% \mathrm{NaOH}$. Thus, being accessible in extraction with $5 \% \mathrm{NaOH}$, the highly ramified xylan fraction contained up to 9 uronic units per 100 Xylp moieties and contributed to $60-70 \%$ of the total xylan content in the pulp. This xylan fraction was also readily removed from the pulp with $10 \% \mathrm{NaOH}$ during the first 15 min of extraction as follows from the composition of released xylan (Figure 4). However, because of the subsequent removal for a longer extraction period of xylan with the much lower branched structure, the average DS with the uronic units fell dramatically. Hence, the studied pulp was composed of two xylan fractions: one was more ramified and readily dissolved in $5 \% \mathrm{NaOH}$, and the other was less ramified and was soluble only in $10 \% \mathrm{NaOH}$, contributing roughly to $30 \%$ of the total xylan content.

These experimental results are in tune with the widely recognized model of cell wall polysaccharides association presuming the intimate association of cellulose and polyoses, where around one-third polyoses are tightly bound to the cellulose fibrils and two-thirds are localized in the space between the fibrils (Kerr and Goring 1975). This assembly in hardwood xylem is explained by plant physiologists by two periods in xylan deposition during the cell wall formation, when the first portion of xylan is bound with cellulose immediately during fibril formation and the second is deposited in the later phase of cell wall development (Awano et al. 2001; Gorshkova et al. 2010) that also may differ among cell types (Kim et al. 2012). It is believed that xylan of the first type is distributed as a thin layer along cellulose microfibrils being compatible with them, also due to low ramification of the backbone, whereas xylan of the second type interacts mainly with lignin and other hemicelluloses in the interfibrillar space and is more ramified than the first one. The structural differences of xylans in hardwoods in terms of the frequency of substitution with both uronic moieties and acetyl groups were detected when analyzing their primary structure by different mass spectrometry techniques (Jacobs et al. 2001; Gonçalves et al. 2008). Several model studies supported an idea that less branched xylan is stronger attached to fibrils than branched (Linder et al. 2003; Bosmans et al. 2014). It is noteworthy that under conditions of kraft pulping, xylan lost almost all acetyl groups and a significant portion of the uronic moieties and was therefore much less branched than the original xylan in the wood, which should improve its retention in the pulp (Pinto et al. 2005a,b). Moreover, xylan can migrate within the fiber cell wall during pulping and bleaching operations (Dahlman et al. 2003; Lisboa et al. 2009; Lekha et al. 2018).

According to the aforementioned fundamentals, it could be speculated that the first rapid kinetics of pulp alkali extraction (Figures 3 and 4) is attributed to the removal of accessible xylan, essentially from the 
interfibrillar space. This xylan is characterized by relatively high ramification with uronic residues, also linked to concomitant hemicelluloses (e.g. to arabinogalactan). Then, the second slow-extraction kinetics can be attributed to the poorly accessible xylan captured by laterally interacting fibrils that need higher swelling in alkaline solution to separate the fibrils as it is shown in Figure 5. This disaggregation of fibrils and the extraction of aligned xylan macromolecules was possible with $10 \%$ $\mathrm{NaOH}$ solution only. The importance of fibril disaggregation on the accessibility of associated xylan was also evidenced by forced hydration employing ultra-high hydraulic pressure treatment of pulp fibers followed by enzymatic hydrolysis (Ferreira et al. 2011).

\section{Accessibility of xylan with respect to its allocation in pulp fibers}

The accessibility of xylan in different morphological zones of pulp fibers during alkaline extraction was assessed employing enzymatic peeling by xylanase. Hydrolytic enzymes act gradually inside the pulp fibers and allow assessing the chemical composition of fibers layer by layer while sampling the hydrolysate along the treatment (Sjöberg et al. 2005). Figure 6 reveals the integral and differential curves of enzymatically treated initial and alkali-extracted pulps with 5 and $10 \% \mathrm{NaOH}$ for $2 \mathrm{~h}$. The differential curve of the initial pulp was trimodal, discriminating the xylan fractions accessible in the periods of $10-20,30-40$ and $50-70$ min of enzymatic hydrolysis. The pulp extracted with $5 \% \mathrm{NaOH}$ showed only one maximum at 30-40 min of hydrolysis and the pulp extracted with $10 \% \mathrm{NaOH}$ at $40-50 \mathrm{~min}$ of hydrolysis. These results were interpreted in terms of the location of the removed xylans as follows: (i) xylan is removed during alkaline extraction predominantly from the outer layers of pulp fibers and, probably, from the lumen side; (ii) the residual xylan after alkaline extraction occurs in the inner areas of the pulp fibers, not necessarily in the same ones when extracted with 5 or with $10 \% \mathrm{NaOH}$.

The easy extraction of xylan from the fiber surface by alkali solutions was widely reported previously (Hansson 1970; Scott 1984; Genco et al. 1990; Dahlman et al. 2003; Lisboa et al. 2005; Lisboa et al. 2009). For the refined/ damaged fibers and fines, the xylan extraction from the lumen side of the cell wall may also be significant (Scott 1984; Lisboa et al. 2009). This probably was a reason for the decrease in accessible xylan content after the alkali extraction at hydrolysis periods higher than $50 \mathrm{~min}$ (Figure 6). The migration of xylan from the inner regions of the cell wall to the periphery can also take place under alkaline extraction (Dahlman et al. 2003; Lisboa et al. 2009) and could be a reason for the shift in the maximum of hydrolysis time observed with 5 and $10 \% \mathrm{NaOH}$ extraction of pulp (Figure 6).

\section{Conclusions}

The results of this study showed that the maximum removal of xylan from refined HBKP coincides with the maximum swelling of pulp in $10-12 \% \mathrm{NaOH}$ solutions, thus confirming that the accessibility of xylan was the predominant factor compared with its solubility in $\mathrm{NaOH}$ solutions of different concentrations. It has also been confirmed that refining prior to extraction increases the yield of xylan. It has been suggested that eucalyptus BKP contains two types of xylans

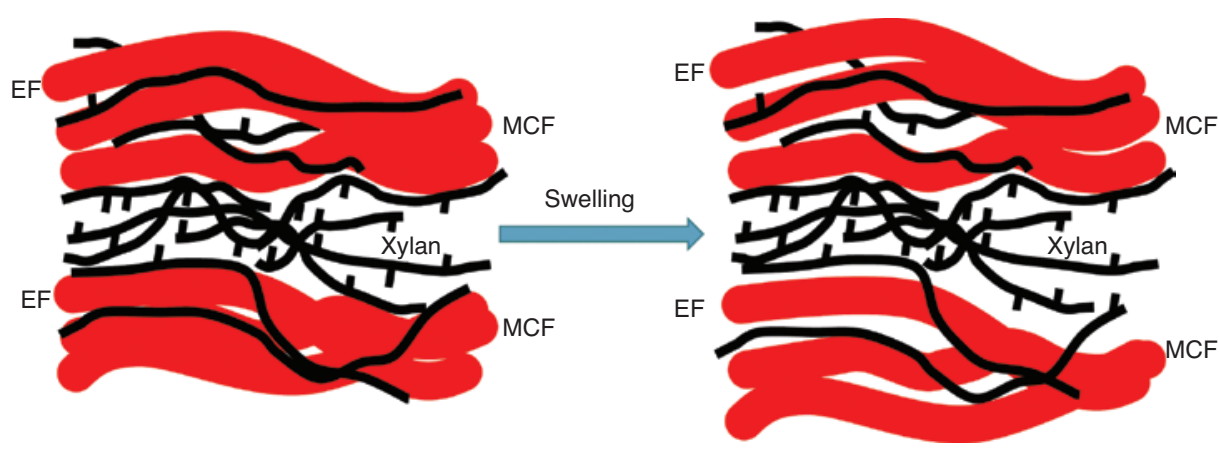

Figure 5: The second slow-extraction kinetics can be attributed to the poorly accessible xylan captured by laterally interacting fibrils that need higher swelling in alkaline solution to separate the fibrils. The kinetics of xylan extraction from pulp were studied in $10 \% \mathrm{NaOH}$ solution. Schematic representation of cell wall swelling of pulp fibers in alkaline solution. Xylan molecules (black chains) are aligned around fibrils (EF, red color) and localized in the space between the fibrils being captured by their lateral interaction while assembled in microfibrils (MF). In the swollen cell wall, the xylan molecules are loosened and more easily removed from the fiber bulk into the solution. 

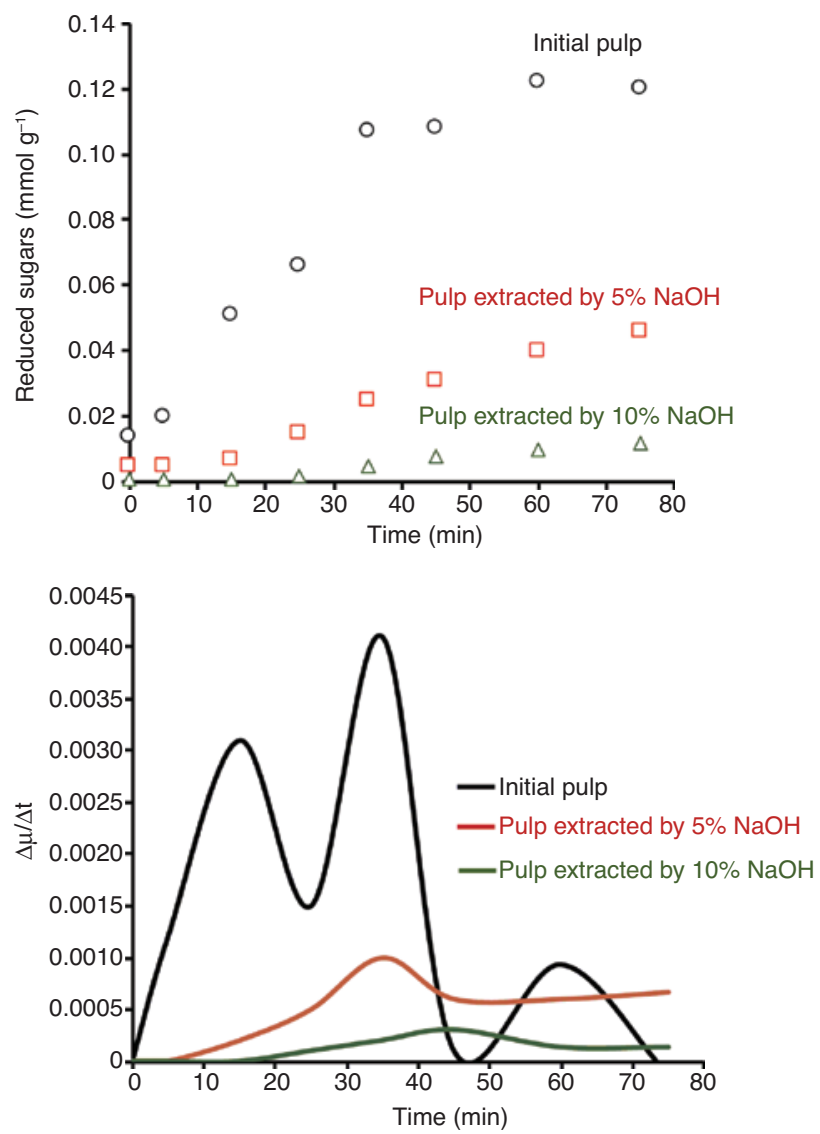

Figure 6: Integral (upper figure) and differential (low figure) curves of enzymatic hydrolysis of initial and alkali-extracted bleached eucalypt kraft pulps.

differentiated by chemical structure, molecular weight and allocation. One type of xylan, contributing to two-thirds of the total xylan in pulp, is soluble in $5 \% \mathrm{NaOH}$ solution and has a relatively high branching with uronic moieties. Presumably, this xylan is preferentially located in the interfibrillar space, essentially in the outer layers of the cell wall. Another xylan is accessible only with $10-12 \% \mathrm{NaOH}$ solutions due to the superior swelling of the cell wall and is much less branched than xylan accessible in $5 \% \mathrm{NaOH}$ solution. This xylan is apparently more tightly bound to the aggregated cellulose fibrils, and most of it is located in the inner layers of the cell wall. It was proposed that the heterogeneity of xylan could be due both to the original occurrence in the cell wall and to the structural changes and spatial rearrangements that occur during pulping and bleaching.

Author contributions: All the authors have accepted responsibility for the entire content of this submitted manuscript and approved submission.

Research funding: This work was financially supported by the CICECO-Aveiro Institute of Materials, within the scope of the project POCI-01-0145-FEDER-007679 (FCT Ref. UID/ CTM/50011/2013), financed by national funds through the FCT/MEC and co-financed by FEDER under the PT2020 Partnership Agreement and by ERDF Funds through the Operational Competitiveness Program - COMPETE, in the frame of the project "NMC - New cellulosic materials" - FCOMP-01-0202-FEDER-034169.

Employment or leadership: None declared.

Honorarium: None declared.

\section{References}

Arnoul-Jarriault, B., Lachenal, D., Chirat, C., Heux, L. (2014) Upgrading softwood bleached kraft pulp to dissolving pulp by cold caustic treatment and acid-hot caustic treatment. Ind. Crops Prod. 65:565-571.

Awano, T., Tanabe, K., Fujita, M. (2001) Xylan and lignin deposition on the secondary wall of Fagus crenata fibers. In: Molecular Breeding of Woody Plants. Eds. Morohoshi, N., Komamine, A. Elsevier Science B.V., Amsterdam, pp. 137-142.

Bosmans, T.J., Agnes, M., Stépán, A.M., Toriz, G., Renneckar, S., Karabulut, E., Wågberg, L., Paul Gatenholm, P. (2014) Assembly of debranched Xylan from solution and on nanocellulosic surfaces. Biomacromolecules 15:924-930.

Browning, B.L. Methods of Wood Chemistry, Vol. 2. Intersci. Publ., New York, 1967.

Budtova, T., Navard, P. (2016) Cellulose in $\mathrm{NaOH}-$ water based solvents: a review. Cellulose 23:5-55.

Clark, J.d'A. Pulp Technology and Treatment for Paper. 2nd Edition. Miller Freeman Publ. Inc., San Francisco, 1985.

Deutschmann, R., Dekker, R. (2012) From plant biomass to biobased chemicals: latest developments in xylan research. Biotechnol. Adv. 30:1627-1640.

Dahlman, O., Jacobs, A., Sjoberg, J. (2003) Molecular properties of hemicelluloses located in the surface and inner layers of hardwood and softwood pulps. Cellulose 10:325-334.

Ebringerová, A. (2006) Structural diversity and application potential of hemicelluloses. Macromol. Symp. 232:1-12.

Evtuguin, D., Tomás, J., Silva, A., Pascoal Neto, C. (2003) Characterization of an acetylated heteroxylan from Eucalyptus globulus Labill. Carbohydr. Res. 338:597-604.

Ferreira, A.R.F.C., Figueiredo, A.B., Evtuguin, D.V., Saraiva, J.A. (2011) High pressure pre-treatments promote higher rate and degree of enzymatic hydrolysis of cellulose. Green Chem. 13:2764-2767.

Genco, J.M., Busayasakul, N., Medhora, H.K., Robbins, W. (1990) Hemicellulose retention during kraft pulping. TAPPI J. 73:223-233.

Gonçalves, V., Evtuguin, D.V., Domingues, M.R. (2008) Structural characterization of acetylated heteroxylan from the natural hybrid Paulownia elongate/Paulownia fortunei. Carbohydr. Res. 343:256-266.

Gorshkova, T.A., Gurjanov, O.P., Mikshina, P.V., Ibragimova, N.N., Mokshina, N.E., Salnikov, V.V., Ageeva, M.V., Amenitskii, S.I., Chernova, T.E., Chemikosova, S.B. (2010) Specific type of secondary wall formed by plant fibers. Russ. J. Plant Physiol. 57:328-341. 
GOST 7516-85 (1985) Pulp. Method for determination of swelling. Hansson, J. (1970) Sorption of hemicelluloses on cellulose fibres.

Part 3. The temperature dependence on sorption of birch xylan and pine glucomannan at kraft pulping conditions. Svensk Papperstidn. 73:49-53.

He, L., Guan, Q.Q., Peng, L.C., Chen, K.L., Chai, X.S. (2017) Improvement of alkali efficiency for purification of dissolving pulp by a modified cold caustic extraction process. Carbohydr. Polym. 178:412-417.

Hubbe, M.A. (2014) Prospects for maintaining strength of paper and paperboard products while using less forest resources: a review. BioResources 9:1634-1763.

Jacobs, A., Larsson, P.T., Dahlman, O. (2001) Distribution of uronic acids in xylans from various species of soft- and hardwood as determined by MALDI mass spectrometry. Biomacromolecules 2:979-990.

Kim, J.S., Sandquist, D., Sundberg, B., Daniel, G. (2012) Spatial and temporal variability of xylan distribution in differentiating secondary xylem of hybrid aspen. Planta 235:1315-1330.

Kerr, A.J., Goring, D.A.I. (1975) The ultrastructural arrangement of the wood cell wall. Cellul. Chem. Technol. 9:563-573.

Krässig, H.A. Cellulose - Structure, Accessibility and Reactivity. Ed. Huglin, M.B. Polymer Monographs, 11th ed. Gordon and Breach Science Publishers, Amsterdam, 1993.

Laine, C., Kemppainen, K., Kuutti, L., Varhimo, A., Asikainen, S., Grönroos, A., Määttänen, M., Buchert, J., Harlin, A. (2015) Extraction of xylan from wood pulp and brewer's spent grain. Ind. Crops Prod. 70:231-237.

Lekha, P., Bush, T., Pammenter, N., Sitholè, B., Berjak, P. (2018) Quantitative assessment of xylan distribution across the secondary cell wall layers of Eucalyptus dissolving pulp fibres. Holzforschung 72:1-8.

Li, J., Liu, Y., Duan, C., Zhang, H., Ni, Y. (2015) Mechanical pretreatment improving hemicelluloses removal from cellulosic fibers during cold caustic extraction. Bioresour. Technol. 192:501506.

Linder, A., Bergman, R., Bodin, A., Gatenholm, P. (2003) Mechanism of assembly of xylan onto cellulose surfaces. Langmuir 19:5072-5077.

Lisboa, S.A., Evtuguin, D.V., Pascoal Neto, C., Goodfellow, B.J. (2005) Isolation and structural characterization of polysaccharides dissolved in Eucalyptus globulus kraft black liquors. Carbohydr. Polym. 60:77-85.

Lisboa, S.A., Evtuguin, D.V., Pascoal Neto, C. (2009) Study on the xylan precipitation in E. globulus pulp during kraft pulping. Proceedings of International Symposium on Wood, Fiber and Pulping Chemistry, June 15-18, Oslo, Norway, 0-027.

Miller, G.L. (1959) Use of dinitrosalicylic acid reagent for determination of reducing sugar. Anal. Chem. 31:426-428.

Nikitin, N.I. Chemistry of Wood and Cellulose. Acad. Sci. USSR, Moscow, 1962, pp. 185-272.
Pääkkönen, T., Dimic-Misic, K., Orelma, H., Pönni, R., Vuorinen, T., Maloney, T. (2016) Effect of xylan in hardwood pulp on the reaction rate of TEMPO-medicated oxidation and the rheology of the final nanofibrillated cellulose gel. Cellulose 23:277-293.

Pinto, P.C., Evtuguin, D.V., Pascoal Neto, C. (2005a) Structure of hardwood glucuronoxylans: modifications and impact on pulp retention during wood kraft pulping. Carbohydr. Polym. 60:489-497.

Pinto, P.C., Evtuguin, D.V., Pascoal Neto, C. (2005b) Effect of structural features of wood biopolymers on hardwood pulping and bleaching performance. Ind. Eng. Chem. Res. 44:9777-9784

Prozil, S.O., Evtuguin, D.V., Cruz Lopes, L.P. (2012) Structural characterization of polysaccharides isolated from grape stalks of Vitis vinifera L. Carbohydr. Res. 356:252-259.

Quaresma, A.C., Dias, V.M., Magina, S.P., Evtuguin, D.V. (2015) Modification of xylan from E. globulus kraft pulp for packaging applications. Proceedings of 18th International Symposium of Woo, Fiber and pulping Chemistry, September 9-11, Vienna, Austria, vol. 1, 298-302.

Richter, G.A., Glidden, K.E. (1940) Cellulose sheet swelling. Effect of temperature and concentration of sodium hydroxide solution. Ind. Eng. Chem. 32:480-486.

Salgueiro, A.M., Evtuguin, D.V., Saraiva, J.A., Almeida, F. (2016) High pressure-promoted xylanase treatment to enhance papermaking properties of recycled pulp. Appl. Microbiol. Biotechnol. 100:9885-9893.

Saukkonen, E., Lyytikäinen, K., Backfolk, K. (2012) Alkaline xylan extraction of bleached kraft pulp - effect of extraction time on pulp chemical composition and physical properties. TAPPI J. 11:37-43.

Scott, R.W. (1984) Hemicellulose distribution in pulp fibers and alkaline extraction rates. J. Wood Chem. Technol. 4:199-218.

Sixta, H. Pulp purification. In: Handbook of Pulp, Vol. 2. Wiley-VCH Verlag GmbH, Weinheim, 2006, pp. 933-965.

Sjöberg, J., Potthast, A., Rosenau, T., Kosma, P., Sixta, H. (2005) Cross-sectional analysis of the polysaccharide composition in cellulosic fiber materials by enzymatic peeling/high-performance capillary zone electrophoresis. Biomacromolecules 6:3146-3151.

Sjöström, E. Pulping chemistry. In: Wood chemistry. Fundamentals and Applications, 2nd Ed. Academic Press Inc, London, UK, 1993, pp. 104-145.

Sousa, C.T., Amaral, J.L. (2017) Hardwood kraft pulp structural features affecting refinability. Holzforschung 71:619-624.

Vuorinen, T., Alén, R. (1999) Carbohydrates. In: Analytical methods in wood chemistry, pulping and papermaking. Eds. Sjostrom, E., Alén, R. Springer-Verlag, Berlin, pp. 37-76.

Wedin, H., Sevastyanova, O., Evtuguin, D.V., Ragnar, M., Lindström, M.E. (2013) Impact of extended-impregnation cooking on the xylan structure in Eucalyptus urograndis kraft pulps. Nordic Pulp Pap. Res. J. 28:498-505. 